\title{
UNIFEM, CEDAW and the Human Rights-based Approach
}

\section{Helen Hintjens}

CEDAW and the Human Rights-based Approach to Programming. New York: UNIFEM, 2007. The pdf of this document can be downloaded at: http://www.unifem.org/resources/item_detail.php?ProductID=94

\section{INTRODUCTION}

Global governance in an era of human rights is beset by a number of unavoidable paradoxes. One is that as more states are increasingly held accountable for fulfilling legal obligations towards citizens, the same states are also obliged to collude in economic and financial deregulation processes that undermine and challenge both state sovereignty and the state's ability to protect the vulnerable among their own populations. In this wider context, the Convention on the Elimination of All Forms of Discrimination against Women (CEDAW) obliges governments to promote, protect and fulfil the equal rights of men and women in their own jurisdictions. In what amounts to the promotion of global governance for gender justice, the United Nations Development Fund for Women (UNIFEM) plays a leading role within the UN system in making sure gender policies are co-ordinated and mainstreamed, and CEDAW is adhered to. Lee Waldorf is the lead editor of this report, as well as some other significant UNIFEM publications. This report will be referred to hereafter as UNIFEM-CEDAW (2007). It will be considered in the context of the recently published UNIFEM Strategic Plan for 2008-2011 (UNIFEM-Plan, 2007).

The UNIFEM-CEDAW report is important, since it explicitly connects the full range of UNIFEM activities to the UN mandate to oversee the implementation of CEDAW provisions. UNIFEM has been given an unambiguous role as 'key driver of gender equality in the context and mechanisms of United Nations reform' (UNIFEM-CEDAW, 2007: 17). This makes the organization the vital link in the 'joined up approach' proposed in this report, and advocated by the former Secretary General, Kofi Annan. One of the underlying issues that Waldorf and UNIFEM seek to address in this 
report is the fragmentation of gender-related UN agencies. The chaos of separate UN gender initiatives has often been a cause of complaint and handwringing in the past. A lot now depends on UNIFEM being able to bring the various existing initiatives together, part of its allotted mission under the new UNIFEM Strategic Plan for 2008-2011. Not surprisingly, the severe resource constraints on UNIFEM are not discussed in Waldorf's short, userfriendly CEDAW report. But it may be helpful to be aware of how budgetary limitations restrict the organization. Financial constraints, as detailed in the UNIFEM Strategic Plan for 2008-2011, are severe and could in future compromise the work on 'women's empowerment and gender equality' which is UNIFEM's key task. It may be that the continuing limitations on funding, here as elsewhere in the UN system, may reduce the agency's room for manoeuvre in the longer-term. If UNIFEM is to remain a 'key driver' of institutional change in the UN CEDAW and wider 'gender' system, then it needs to be properly funded on a predictable basis. This question is returned to briefly at the end of this piece.

The report by Waldorf clearly sets out the main issues for UNIFEM in the CEDAW process. The first is how to support complex multi-lateral processes designed to give CEDAW obligations some real bite. How governments which are often repressive and authoritarian towards their own civil society can be made to feel more accountable for meeting their CEDAW obligations is the six billion dollar question. Should one rely mainly on persuasive, reassuring dialogue which engages with government officials behind-thescenes and is mostly conducted by professional negotiators? How much, and when should UNIFEM make room for more strident voices to come through this 'filter', especially from civil society groups who form the counterweights of responsible ministries and agencies? By supporting both negotiations and networks of women's NGOs and civil society groups, UNIFEM has tried to do both at once. The preferred strategy seems to be to adopt a supportive position in relation to what are sometimes very minor improvements by government, whilst at the same time underwriting the shadow reporting processes built into CEDAW's own mechanisms of reporting and comment. The question then is to show how these UNIFEM initiatives help transform gender relations towards greater equality, and how gender justice can become a more widely shared policy priority within the UN system and among member states.

The UNIFEM-CEDAW report exposes some contradictions between the principles and institutions of the international legal CEDAW machinery, and the priorities and working habits of UNIFEM. It is not the only UN agency trying to bring gender equality work into the centre of the picture. But UNIFEM is supposed to play a role as a catalyst for the overall CEDAW process globally, and this objective has to be balanced within UNIFEM with its role as lead UN agency for promoting gender equality and a human rightsbased approach (HRBA) within the UN system internally. If UNIFEM's impact could be measured on a 'catalometer', perhaps we could determine 
how effective the organization is. But measuring catalysing impacts, which are by definition indirect, is notoriously problematic. As it is, UNIFEM must generate gender-equality promoting change at government level and inside the UN, and must demonstrate its impact one way or another. Perhaps the main puzzle in relation to this UNIFEM-CEDAW report is how UNIFEM's impact can be assessed in relation to the realization of gender equality.

\section{AN EVOLVING UN GENDER AGENDA}

The UNIFEM-CEDAW report is clearly written and very accessible. It follows on another short report produced in 2006 on CEDAW and Security Council Resolution 1325: a Quick Guide, by Shelly Inglis, Maha Muna and Waldorf herself, among others (UNIFEM, 2006). ${ }^{1}$ The lucid style and accessible layout of both reports expresses how seriously UNIFEM takes its own responsibility to promote wider awareness of CEDAW, including in the UN. Its mandate spans the CEDAW process, which is explicitly linked to moves inside the UN to move all agencies to adopt a human-rights based approach in all their operations. The context of this report, therefore, is growing pressure on all UN agencies, including UNIFEM, to come up with 'concrete evidence and knowledge on the "how to" of gender equality' (UNIFEM-CEDAW, 2007: 26). Producing hard evidence of efficacy and indicators of performance will be a challenge.

UNIFEM's new role has arisen in response to persistent - and understandable — demands to create more consistency among UN agencies dealing with what is termed the gender architecture. Wider institutional changes are stalled, in the wake of the 'One UN' reforms, which have been subject to tedious political negotiations and lengthy and uncertain resource mobilization, and so are still not agreed. ${ }^{2}$ In this context, UNIFEM may need a more proactive view of itself as it seeks to plug the gap between the present fragmented realities of UN gender agencies, and an imagined future of reformed and unified UN structures. Gender advocates in the UN are understandably cautious about the trend towards 'centralizing' strategic CEDAW goals under UNIFEM. Under less gender-sensitive leadership, centralization and

1. The report summary explains that: 'While both sets of standards are important in their own right, there is also a synergy between them that can enhance their implementation and impact. UNSCR 1325 helps to broaden the scope of CEDAW's application by clarifying its relevance to all parties in conflict and in peace. CEDAW, in turn, provides concrete strategic guidance for actions to be taken on the broad commitments outlined in UNSCR 1325. Drawing on these instruments together will enable advocates to maximize the impact of norms and standards for gender equality in all conflict and post-conflict interventions'.

2. 'The aim is to... reduce duplication and transaction costs so that the UN can use resources more effectively to support partner countries to achieve their development goals' on http://content.undp.org/go/newsroom/2007/february/un-pilot-reform-20070201. en;jsessionid=axbWzt8vXD9 (accessed 7 September 2008). 
re-unifying the UN agencies, including the gender-related agencies, might even constrict rather than smooth the path of work on gender equality in terms of setting the agenda and taking effective initiatives to realize gender equality and women's rights.

Perhaps the recent move of the CEDAW Committee from New York to Geneva, where the Committee falls directly under the Office of the High Commissioner for Human Rights, will facilitate UNIFEM's new coordinating and articulating role. However UNIFEM headquarters remain in New York, and there remains considerable fragmentation among UN agencies promoting gender equality, including DAW (Division for the Advancement of Women), UNIFEM itself and OSAGI (Office of the Special Advisor on Gender Issues and Advancement of Women). An important step in their co-ordination, besides relocation, is that their primary shared task is now to help monitor implementation of CEDAW by governments worldwide. To this extent, all the gender-related agencies' agendas now overlap and they should be increasingly focused on exploring their complementarities, rather than competing or ignoring one other.

From around the mid-1990s, the UN started proactively to reintegrate human rights into its internal operations. Since 2002, a positive commitment has been made to mainstream a human rights-based approach across all UN agencies and programmes. Waldorf explains this in some detail in her UNIFEM-CEDAW report. Prioritizing gender equality and empowerment becomes a way of also ensuring the commitment of $\mathrm{UN}$ agencies to a human rights-based approach. Gender equality is brought into all programming and given a practical form of expression.

According to this report, UNIFEM seemed to have taken on the role of 'key driver' of gender equality inside the UN system long before being allocated that role formally under the 2008-10 plan. One factor that served to bring UNIFEM into the centre of the CEDAW process was its own strength as catalyst. If it has a specific role, the agency seems marked by an ability to persuade others, especially governments, that it is in their interest to adopt a more rights-based approach to gender equality. In the context of mainstreaming human rights-based approaches across the UN system (UNIFEM-CEDAW, 2007: 5), UNIFEM has a good track record. It has emerged as relatively flexible and responsive to those governments and coalitions of actors willing to innovate in gender-responsive social technologies.

The expectation is that, following success with more human rights-based approaches to gender equality, governments may be willing to relate to the UN mandates in other respects, and to civil society, in a more 'rights-based' way. The whole process of mainstreaming the human rights-based approach, understood as incorporating gender equality rights, is thus geared towards promoting national ownership of CEDAW goals by governments. The main danger is of UNIFEM being mainly responsive rather than initiating new schemes to promote government compliance with CEDAW's provisions. 


\section{NOT EVERYTHING THAT COUNTS CAN BE COUNTED}

So, the problem remains. Potential funders need reassurance that further rapid increases in UNICEF's funding (which doubled from 2003 to 2007) are justified on the basis of past performance, before more funds are allocated. This is one issue which the UNIFEM Strategic Plan for 20082011 proposes to resolve: '[by] doubling [UNIFEM's] total resource base' (UNIFEM-Plan, 2007: 26), not once but twice during the 2008-2011 period. The role of UNIFEM - as depicted in the UNIFEM-CEDAW report - is mainly to get other agencies in the UN, NGOs and government ministries, lawmakers and others to take their gender equality obligations seriously. It is not always possible to identify just what is being delivered: is it mainly a human rights-based, results-driven and gender-sensitive approach to programming? Or can a human rights-based approach also deliver better results in other ways; can it deliver anything new (UNIFEM-CEDAW, 2007: 28-37)?

From the UNIFEM-CEDAW report, it is clear that UNIFEM's major role in the CEDAW process is as catalyst rather than initiator of complianceenhancing measures on the part of governments and civil society actors. Since 'human rights are essentially about a relationship between governments and people', the role of UNIFEM is to work away behind the scenes and encourage national governments to own the goal of respecting, promoting and fulfilling women's rights in the longer-term (UNIFEM-CEDAW, 2007: 24-5). Section 3 of the report recognizes the role of UNIFEM in getting governments to 'recognise and have political will for women's rights' and confesses that for this purpose there is 'no standard procedure or rulebook' (UNIFEM-CEDAW, 2007: 36). There are many recipes for success and failure. On the way the best UNIFEM can be is a broker, a negotiating organization, seeking to make a difference in the global efforts to translate CEDAW into reality on the ground. If governments feel increasingly obliged, encouraged or even shamed into overturning discriminatory laws, then UNIFEM can take at least some credit for this. As a bridging institution between CEDAW instruments and national governments, but also between the UN gender equality agenda and civil society groups and NGOs in many UN member countries, UNIFEM and its staff have their work cut out for them.

Negotiating behind the scenes can be hard to reconcile with another UN priority, also discussed by Waldorf in some detail in this report, namely achieving 'results-based management'. This principle is applied across all UN agencies. The task of unearthing what is 'really' happening to women's rights in different countries is, however, greatly facilitated by the UNIFEM-supported 'shadow reporting' process in which NGOs, and especially women's organizations, comment on the official CEDAW report of the national government (UNIFEM-CEDAW, 2007: 10-12). This 
shadow reporting process is closely supported in a number of countries by UNIFEM.

In line with Waldorf's emphasis on the importance of a contextual analysis, CEDAW and the Human Rights-based Approach to Programming suggests that UNIFEM has a keen awareness of the importance of contextualizing all human rights-based work. The report suggests that: '(a) universal set of gender equality requirements could actually be an obstacle rather than an asset for gender equality work, if it was too abstract or rigid' (UNIFEMCEDAW, 2007: 13). What are needed, it suggests, are rough guidelines that can be tailored to local contexts to help work out specific implementation strategies. This suggests that lists of indicators of national-level impacts and outcomes will not be that useful. According to the report: 'The fundamental innovation of the substantive model of equality is to use the conditions of women's actual lives, rather than the wording used in laws, as the true measure of whether equality has been achieved' (UNIFEM-CEDAW, 2007: 52, emphasis added).

CEDAW's substantive model of equality is one of its original features. Equality, it is recognized, implies more than the absence of gender discrimination. It implies equality which recognizes real structural disadvantages suffered by women compared to men, ceteris paribus. Such structural inequality between men and women's lives can be imagined, for example, in relation to property, to work or reproductive rights. But knowing how to adapt policies to take such inequalities on board is not easy or straightforward.

The substantive model of equality inside CEDAW thus has substantive implications for UNIFEM, for UNICEF and other UN agencies associated with the human rights-based approach to programming. Each agency has its own approach; and it is not surprising that UNIFEM is 'ahead of the game' in relation to gender equality rights. But UNIFEM can also learn a great deal from an agency like UNICEF, which for some years has worked at different levels simultaneously: (i) at the macro, national or regional levels to help reform laws and policies; (ii) at the meso level supporting institutions, advocacy and evaluation capacities; and (iii) at the micro level in communities, to shift attitudes towards a more rights-based culture and overall value system (UNIFEM-CEDAW, 2007: 25). In many respects, UNIFEM is catching up with this approach, and seeking greater involvement at the level of meso and grassroots organizations than in the past. One way it is doing this is through increased involvement in advocacy and shadow reporting activities.

UNIFEM starts from a concern with substantive rather than formal equality of women. This means the agency's goal will require it to work at several levels at once, just like UNICEF. Working at different levels is not about working sequentially, but in tandem. Laws and policies must be reformed to protect - at the same time that institutions need to be made to work to promote - gender equality in practical ways, and gender-biased cultural 
attitudes need to be revisited, for gender equality exists so that women's rights can be fulfilled. Critical to the overall success of UNIFEM's approach has been what Waldorf calls a full 'situation analysis' of the context. Through such an analysis, the specific framing of rights, capacities and responsibilities in any particular situation can be better understood. Arguably this reduces the chances of making mistakes and wasting time in realizing rights (or more precisely in having governments realize rights) (UNIFEM-CEDAW, 2007: $31,41-4)$.

Waldorf is clear that relying on a formal, legal approach to human rights will not by itself bring about real and substantive equality between men and women. In line with this: 'The fundamental innovation of the substantive model of equality is to use the conditions of women's actual lives, rather than the wording used in the laws, as the true measure of whether equality has been achieved' (UNIFEM-CEDAW, 2007: 52). This is one of the central themes of this report and of UNIFEM and CEDAW's approach to the human rights-based approach. Waldorf is intent, in this report, on popularizing the mission of UNIFEM. Securing full government compliance with CEDAW is a dream, but it is one that inspires UNIFEM staff. The report could do with being regularly updated but should remain just as sparse, clear and down-to-earth as it is now.

UNDP has produced Indicators for Human Rights Based Approaches to Development: a User's Guide. But 'rights-based' policies need to be translated into ways of working with local people, especially with women and those who represent them. This translation process can sometimes be cumbersome, as participants noted during a human rights and governance 'refresher course' in the Philippines, run by the Philippines Human Rights Commission with Institute of Social Studies (ISS) staff in 2006. While the UNDP approach may help promote a better understanding of human rights, it is the arduous task of local UNIFEM staff to translate CEDAW's wording and a rights-based approach into language that makes sense to women's NGOs, for example, in the local setting of the Philippines. This process of 'grounding' CEDAW has some very practical implications. Before women's equality concerns can start to be addressed in ways that have resonance with national and local situations, the role of UNIFEM is to help contextualize CEDAW provisions and the human rights-based approach.

Under CEDAW, state parties are obligated in various ways, and the mechanics of this are explained in simple terms in the UNIFEM-CEDAW report. Poor and vulnerable women have a key role in promoting gender equality, and this is made clear. The litmus test of a HRBA is whether it can support the most marginalized women to undertake their own rightspromoting initiatives and exercise their rights more successfully. The last section of UNIFEM-CEDAW report, 'Women's Human Rights in Depth', provides detailed and very accessible summaries of the CEDAW Articles, of its Recommendations and of the Optional Protocol. The online pdf also 
includes website links, key readings and links to other organizations working to promote women's rights and gender equality and to support the CEDAW process.

\section{A SUBSTANTIVE MOVE TOWARDS EQUALITY? THE PHILIPPINES CASE}

Some positive experiences have emerged from countries such as the Philippines, an example briefly considered in this section. In the Philippines, the wider context of UNIFEM's work is the CEDAWSEAP programme ('Facilitating CEDAW Implementation Towards the Realization of Human Rights in South East Asia'). This programme, which operates in seven countries of East and South-East Asia (Cambodia, Indonesia, Laos, Philippines, Thailand, Timor-Leste and Vietnam), supports women's NGOs and trains them on CEDAW provisions and processes. The main idea is to enhance the local organizations' ability to gather and independently analyse available data. National and local NGOs use these data to make their own collective recommendations in individual country shadow reports. The CEDAWSEAP programme also trains NGO representatives in how to present shadow reports and how to engage in dialogue with CEDAW experts during CEDAW Committee sessions in Geneva.

In most South East Asian countries, NGOs had not fully understood the nature of CEDAW prior to UNIFEM intervention. Not knowing how the shadow report could be compiled, why it was vital to do this, and why it mattered that evidence should be effectively presented, all undermined processes of holding governments accountable for meeting their CEDAW obligations. It was UNIFEM's work to promote an environment conducive to CEDAW implementation, that encouraged a number of Philippino women's NGOs to file a shadow report in 2006 - the second time such a report had been filed. The first shadow report in 1997 had involved just nine NGOs. The second involved a staggering ninety-five NGOs in total. This second round of shadow reporting saw Philippino women's NGOs become much more assertive.

The CEDAWSEAP programme is thus a good example of the sheer mix of methods and approaches, levels and techniques UNIFEM needs to use in its role as 'key driver' in the CEDAW process. National, sectoral and local policy review are all important in terms of monitoring government compliance (including of the legislature, executive and judiciary) with CEDAW provisions. To this end, new and more innovative systems of reporting and monitoring compliance have been introduced. Also, on the heels of the 2006 CEDAW shadow reporting process, Philippino women's NGOs and donors supported a multi-sectoral approach to implementing CEDAW Concluding Comments and agreed to jointly monitor actions arising from them. 
UNIFEM in the Philippines has also actively supported briefings and dialogue between the national women's organizations and legislators and staff of both houses of the Philippines Congress. The central issue in these meetings and debates was the need to harmonize national legislation with CEDAW standards. In particular, what was advocated was the enactment of a gender equality charter. In addition reforms were needed to change the law on reproductive health, on women's participation in local sectors, on antimarital infidelity, anti-prostitution and domestic workers' rights. There was support for awareness-building, mobilization among women NGOs around the country, and media publicity to actively lobby for the women's charter, known nationally as the 'Magna Carta for Women'.

Following the second shadow report, a number of Philippino womens' NGOs also used CEDAW provisions to bring a case against the city government of Manila on reproductive rights violations. Moreover the first Optional Protocol case in South East Asia was also filed in the Philippines, where under CEDAW provisions, an individual can go to the CEDAW Committee. This regards a rape case that received a negative ruling in a Philippines court (as it happens, by a woman judge). The case was again brought by a number of women's NGOs on behalf of an individual woman, and was filed on 29 November (acknowledged 3 December 2007). A ruling on this case can be expected some time in early 2009 , and it should be an interesting learning case for future practice. There have been only a handful of Optional Protocol cases worldwide so far. The complaint demanded justice and compensation for the individual victim and also significant reforms in the judiciary, policy reforms and the monitoring of implementation of these proposed changes. Specific gaps in budgets and in legal, medical, psychological and economic support systems were identified, and rectification demanded for rape victims and their families in general. ${ }^{3}$

Advocacy and lobbying were vital parts of UNIFEM's Philippine campaign, especially to counter powerful resistance from conservative religious groups keen to remove all mention of gender equality or reproductive health rights from legislation. The judiciary has been supported by UNIFEM through creation of an academic human rights resource centre. A CEDAWbased training manual and bench book of cases has also been jointly developed for use at the Philippine Judicial Academy, the training arm of the Supreme Court. These resources were used to train several batches of judges, clerks of court and other court personnel, which might just make it less likely in future that resistance to gender equality principles will continue to take the direct, knee-jerk form that it has in the past. As the UNIFEM-CEDAW report also explains, the Optional Protocol of CEDAW provides for individuals and groups to appeal to the CEDAW Committee, and also allows the

3. Pdf file, Communication Procedure under the Optional Protocol to CEDAW, Women's Legal Bureau, Quezon City, Philippines, 29 November 2007. Thanks to Luz Rodriguez of UNIFEM for providing access to this document. 
Committee to make their own inquiries into violations of the Convention (UNIFEM-CEDAW, 2007: 66-7). ${ }^{4}$

\section{CONCLUSION}

Waldorf's brief but timely UNIFEM-CEDAW report coincides with the end of the 2004-07 UNIFEM programming cycle. Agreeably, for a UN document, the report requires little explanation; it is quite transparent in its language, and available online for free, making it highly accessible. For non-experts and those working with NGOs, this short CEDAW guide would be an immensely useful starting point, and can be read as 'sister' to the 2006 CEDAW and Security Council Resolution 1325 study mentioned earlier (UNIFEM, 2006). Both stick to general principles. Neither includes case studies (or even the usual 'boxes' in the text). This makes them widely usable, and useful for anyone who wants to learn more about what CEDAW entails in practice. The UNIFEM-CEDAW report which I have focused on here actively invited more engagement from readers with the CEDAW process and reflection on how gender equality can be achieved in practice.

The general frameworks identified in the UNIFEM-CEDAW 2007 report can be summed up in the reiterated need for a 'situation analysis' in each context. Whether in the Philippines or in the Netherlands, measuring success depends on how CEDAW provisions can be tailored to local possibilities. In the 'translation' and analysis process, women's NGOs and UNIFEM can decide, as UNIFEM in the Philippines decided, to devise their own indicators of success and failure, indicators that may be closer to the ground than some other parts of the UN machinery might like.

To monitor CEDAW compliance, therefore, a key lesson from UNIFEM's experience seems to be that the statistical and oversight system of government must be strengthened before monitoring can mean much. Sexdisaggregated data and gender statistics have to be available, and have to be fed into the government's own management information tracking systems. It is vital, for example, to have measures of violence against women and children, as well as protection from violence of women, trafficking and countertrafficking measures as they affect women and girls, rape and rape assistance, sexual harassment, women's political participation and gender-differentials in wages. Some Philippines NGOs, for example, have subscribed to HURIDOCS, the Human Rights Documentation System, a computer-based

4. A dramatic example is Ciudad Juarez in Mexico, where a CEDAW Inquiry Procedure was activated based on a complaint filed by Mexican women's NGOs against the government. 'Juárez has become a by-word as a result of all the denunciations and demonstrations that the femicides there have provoked, but in other Mexican cities, and particularly in Guatemala, the situation now is extremely serious', reports Teresa Rodríguez, head of UNIFEM for Mexico, Central America, Cuba and the Dominican Republic, to Inter Press Service at http://www.alterinfos.org/spip.php?article675 (accessed 28 January 2008). 
documentation system developed by the Coalition Against Trafficking in Women - Asia Pacific. This documents gender-based violence by region and by country since 1998 . In other cases, a harmonized case study checklist is used so that common parameters can emerge among countries, with a mix of quantitative and qualitative analysis.

In the end, there will be huge tensions in a document which, like the UNIFEM-CEDAW report, tries to condense huge and complex arguments and points of view into a very simply told tale, in a highly accessible format. Wanting to systematize the human rights-based approach can clash with the demand for more creative and innovative approaches, that are more grounded in locally-analysed realities of women's lives, in the substance of what gender equality and inequality implies in particular places for particular people. The report is to be admired for not juxtaposing, as is still too often the case, a bland, universalist conception of human rights with a more substantive, context-sensitive approach. Waldorf advises that: 'In order to implement the HRBA properly, programming should be informed by knowledge of the specific human rights standards that apply, and of the measures that should be taken to further them' (UNIFEM-CEDAW, 2007: 23). She adds that: 'When designing programmes, the full RBM [Rights Based Monitoring guide] should always be used as the core reference' (ibid.: 40). On a daily basis, the trick for UNIFEM staff is working out how to apply the one - RMB in this case - to the other - the 'substantive' context. Creative and standardized methods need not contradict one another. What seems to be needed is a mix of methods, tools and approaches at different levels.

With only a 'project presence' in most countries, UNIFEM is often represented by just one contracted gender expert and one administrative staff member, whose capacity is strictly limited. Contracts are often renewed annually, and may end when project funding ends. This makes it hard for UNIFEM to work at the same level of functionality as more fully-fledged agencies like UNDP, UNICEF and UNFPA (UN Population Fund). It remains a marginal player, coaching and mentoring other UN agency staff, training civil society organizations, and promoting the HRBA. The whole process needs to be repeated even within UN agencies, where short-term contracts mean an increasing proportion of staff come and go.

As UNIFEM and other UN agencies go through major changes, they are also expected to continue initiating major changes outside, especially in making relations between governments and the $\mathrm{UN}$, and governments and their own people, more human rights-based. Amidst the process of ensuring that human rights-based approaches to gender equality become the norm, there is a danger that the uncertainty arising from liberalization of working practices may undermine rights-based accountability within UNIFEM and other UN agencies responsible for CEDAW. Gender equality has become more central to UN internal management and values, as has the human rights-based approach. But when one is only in a job for a year or two, it can be very difficult. To create the bonds of mutual understanding and trust 
that get governments, national institutions, NGOs and women themselves to adopt a more human rights-based approach to gender equality, is at the heart of the CEDAW process.

\section{REFERENCES}

UNDP (2006) Indicators for Human Rights Based Approaches to Development: A User's Guide. New York: UNDP. Free pdf can be downloaded from: http://www.undp.org/oslocentre/ docs06/HRBA\%20indicators\%20guide.pdf

UNIFEM (2006) CEDAW and Security Council Resolution 1325: A Quick Guide. New York: UNIFEM. Free pdf can be downloaded from: http://www.unifem.org/resources/ item_detail.php?ProductID=104

UNIFEM (2007) UNIFEM Strategic Plan for 2008-2011. New York: UNIFEM. Free pdf can be downloaded from: http://www.unifem.org/resources/item_detail.php?ProductID=100

Helen Hintjens is Senior Lecturer in Development and Social Justice at the Institute of Social Studies, PO Box 29776, 2502 LT The Hague, The Netherlands. She has worked on issues of rights and social justice, on genocide and post-genocide politics in Rwanda and on refugee and asylum policies in Europe. She has a strong interest in gender justice issues across the fields of conflict and human rights. 